\title{
Antimicrobial Effects of a Lipophilic Fraction and Kaurenoic Acid Isolated from the Root Bark Extracts of Annona senegalensis
}

\author{
Theophine Chinwuba Okoye, ${ }^{1}$ Peter Achunike Akah, ${ }^{1}$ Charles Ogbonnaya Okoli, ${ }^{1}$ \\ Adaobi Chioma Ezike, ${ }^{1}$ Edwin Ogechukwu Omeje, ${ }^{2}$ and Uchenna Estella Odoh ${ }^{3}$ \\ ${ }^{1}$ Department of Pharmacology and Toxicology, Faculty of Pharmaceutical Sciences, University of Nigeria, Enugu State, \\ Nsukka 410001, Nigeria \\ ${ }^{2}$ Department of Pharmaceutical and Medicinal Chemistry, Faculty of Pharmaceutical Sciences, University of Nigeria, \\ Enugu State, Nsukka 410001, Nigeria \\ ${ }^{3}$ Department of Pharmacognosy and Environmental Medicine, Faculty of Pharmaceutical Sciences, University of Nigeria, \\ Enugu State, Nsukka 410001, Nigeria
}

Correspondence should be addressed to Theophine Chinwuba Okoye, theokuba@yahoo.com

Received 5 January 2012; Revised 20 February 2012; Accepted 20 February 2012

Academic Editor: Victor Kuete

Copyright (C) 2012 Theophine Chinwuba Okoye et al. This is an open access article distributed under the Creative Commons Attribution License, which permits unrestricted use, distribution, and reproduction in any medium, provided the original work is properly cited.

\begin{abstract}
Root bark preparation of Annona senegalensis Pers. (Annonaceae) is used in Nigerian ethnomedicine for treatment of infectious diseases. Extraction of the $A$. senegalensis powdered root bark with methanol-methylene chloride $(1: 1)$ mixture yielded the methanol-methylene extract (MME) which was fractionated to obtain the ethyl acetate fraction (EF). The EF on further fractionation gave two active subfractions, F1 and F2. The F1 yielded a lipophilic oily liquid while F2 on purification, precipitated white crystalline compound, AS2. F1 was analyzed using GC-MS, while AS2 was characterized by proton NMR and X-ray crystallography. Antibacterial and antifungal studies were performed using agar-well-diffusion method with 0.5 McFarland standard and MICs calculated. GC-MS gave 6 major constituents: kaur-16-en-19-oic acid; 1-dodecanol; 1naphthalenemethanol; 6,6-dimethyl-bicyclo[3.1.1] hept-2-ene-2-ethanol; 3,3-dimethyl-2-(3-methylbuta-1,3-dienyl)cyclohexane1-methanol; 3-hydroxyandrostan-17-carboxylic acid. AS2 was found to be kaur-16-en-19-oic acid. The MICs of EF, F1, and AS2 against $B$. subtilis were 180,60 , and $30 \mu \mathrm{g} / \mathrm{mL}$, respectively. AS2 exhibited activity against $S$. aureus with an MIC of $150 \mu \mathrm{g} / \mathrm{mL}$, while F1 was active against $P$. aeruginosa with an MIC of $40 \mu \mathrm{g} / \mathrm{mL}$. However, the extracts and AS2 exhibited no effects against Candida albicans and Aspergillus niger. Therefore, kaurenoic acid and the lipophilic fraction from A. senegalensis root bark exhibited potent antibacterial activity.
\end{abstract}

\section{Introduction}

The increase in the incidence of new and reemerging infectious diseases caused by organisms with high resistance rates to standard antimicrobial agents has been a very challenging and global health burden. The indiscriminate and widespread antimicrobial use continues to cause significant increase in drug-resistant and multidrug-resistant bacteria $[1,2]$. Medicinal plants have long been used in traditional medicine for treatment of various ailments including infectious diseases and many potent phytochemicals or second -ary metabolites possessing antimicrobial effects have been isolated from plants $[3,4]$. These constituents could serve as veritable lead compounds in the science of drug discovery, development, and research. An example is the startling discovery of penicillin from a microscopic plant in 1928 that lead to the synthesis of its derivatives such as penicillin $G$ [5]. It is quite pertinent to note that since the discovery of nalidixic acid in 1962, which led to the synthesis of more potent fluoroquinolones and derivatives [6], there has not been the introduction of any major pharmacological class of antibacterial agents. Hence, this is posing a great challenge to researchers in the area of drug discovery and development of anti-infective agents and has equally lend credence to 
the intensified research going on in the area of natural products for the isolation of potent compounds that could serve as lead in the discovery of new antibacterial agents [7]. Screening of medicinal plants and other natural products has led to the isolation of clinically active antibacterial agents [8]. Interestingly, many plant extracts have shown to possess antimicrobial effects and are being used in traditional medicine $[9,10]$. Annona senegalensis Pers. (Annonaceae) is among the medicinal plants that have been documented to possess antibacterial effects [11-13]. Also the ethnomedicinal uses of the plant in the treatment of wounds and infectious diseases such as diarrhea $[14,15]$ periodontal and other oral infections [16] had been reported. Furthermore, the anticonvulsant, sedative, and muscle relaxant $[17,18]$ as well as anti-inflammatory [19] effects of the root bark extract and fractions of $A$. senegalensis have been reported.

Therefore, the objective of this study was to ascertain the antimicrobial effects of the root bark extracts and fractions of $A$. senegalensis and to isolate and characterize the active phytochemical(s) responsible for these effects using protonNMR and X-ray crystallography.

\section{Materials and Methods}

2.1. Plant Materials. Fresh roots of A. senegalensis were collected from Enugu-Ezike, Enugu State, Nigeria in the month of June, 2007 and authenticated by a taxonomist, Mr. A. O. Ozioko, of the International Centre for Ethnomedicine and Drug Development (InterCEDD), Aku Road, Nsukka, Enugu State, Nigeria. A voucher specimen was deposited at the InterCEDD herbarium (specimen number: BDCP /INTERCEED-64).

2.2. Test Organisms. Clinical strains of Escherichia coli, Bacillus subtilis, Pseudomonas aeruginosa, Salmonella paratyphi and Staphylococcus aureus, Aspergillus, niger and Candida albicans, obtained from the Medical Laboratory Department of Bishop Shanahan Memorial Hospital, Nsukka, Enugu State, Nigeria and preserved in the Microbiology Unit of the Department of Pharmaceutics and Pharmaceutical Microbiology, University of Nigeria, Nsukka, were used. These clinical strains were isolated from designated biological fluids or sources as shown in Table 1.

2.3. Animals. Adult albino mice $(18-30 \mathrm{~g} ; n=14)$ bred in the Laboratory Animal Facility of the Department of Pharmacology and Toxicology, University of Nigeria, Nsukka, were used in the studies. The animals were maintained under standard laboratory conditions and had free access to standard pellets (Guinea Feeds, Nigeria Plc) and water. On transfer to the work area, animals were allowed two weeks of acclimatization before the commencement of the experiments. All animal experiments were conducted in compliance with the National Institute of Health Guidelines for Care and Use of Laboratory Animals (Publication no. 85-23, revised 1985) and approval of the University Ethical Committee on the use of laboratory animals.
TABLE 1: Biological sources of clinical strains of the test organisms.

\begin{tabular}{lcc}
\hline S/No & Clinical strain & $\begin{array}{c}\text { Biological } \\
\text { source }\end{array}$ \\
\hline 1 & Bacillus subtilis & Wound \\
2 & Escherichia coli & Stool \\
3 & Pseudomonas & Wound \\
4 & Salmonella paratyphi & Stool \\
5 & Staphylococcus aureus & Nasal discharge \\
6 & Aspergillus niger & Spoiled food \\
7 & Candida albicans & High vaginal \\
& & swab (HVS) \\
\hline
\end{tabular}

2.4. Preparation and Extraction of Plant Materials. The root barks were peeled off, cut into pieces, and dried under shade. The dried root-bark was then pulverized into coarse powder using a hammer mill. The powdered material $(2.95 \mathrm{~kg})$ was extracted with a mixture of methanol: methylene chloride ( $1: 1)$ using Soxhlet extractor to obtain the methanol: methylene chloride extract or the crude extract (MME). This was concentrated at reduced pressure using a rotary evaporator to obtain a yield of $375 \mathrm{~g}(12.71 \% \mathrm{w} / \mathrm{w})$.

2.5. Solvent-Guided Fractionation of MME and BioactivityGuided Studies. The methanol-methylene chloride extract (MME; $250 \mathrm{~g}$ ) was subjected to solvent-guided fractionation in a silica gel (70-220 mesh, Merck Germany) column, successively eluted with n-hexane, ethyl acetate, and methanol in order of increasing polarity. The fractions were concentrated under reduced pressure in a rotary evaporator (below $40^{\circ} \mathrm{C}$ ) to obtain the hexane fraction (HF; $115 \mathrm{~g} ; 46.0 \% \mathrm{w} / \mathrm{w}$ ), ethyl acetate fraction (EF; $61 \mathrm{~g} ; 24.4 \% \mathrm{w} / \mathrm{w})$, and methanol fraction (MF; $69.5 \mathrm{~g} ; 27.8 \% \mathrm{w} / \mathrm{w}$ ). Bioactivity-guided studies on the extract and fractions using agar well diffusion method showed that EF had a potent antibacterial activity with a relatively higher inhibition zone diameter (IZD) than the HF and MF. Subsequently, the ethyl acetate (EF) soluble fraction was subjected to column chromatographic separation. The EF $(50 \mathrm{~g})$ was separated in a dry-packed silica gel (70-220 mesh, Merck Germany) column of width $4 \mathrm{~cm}$ and length $40 \mathrm{~cm}$. The extract was mixed with the silica gel and loaded on top of the prepacked column. The column was successively eluted with gradient mixtures of n-hexane and ethyl acetate $(1: 0,9: 1,8: 2,7: 3,6: 4$, $5: 5,4: 6,3: 7$, and $2: 8$ ) and the fractions collected in $500 \mathrm{~mL}$ volume. The fractions were subsequently pooled and concentrated to afford eight broad fractions, F1-F8, based on the similarity of constituents visualized on silica gel precoated TLC plates (Uniplate-Analtech Co., USA), developed with mixtures of $n$-hexane and ethyl acetate accordingly. Fraction $\mathrm{F} 1$ gave an oily liquid or lipophilic fraction, while F2 (9-12; $2000 \mathrm{~mL})$ when concentrated yielded white crystals. However, the crystals yielded by F2 were harvested and purified by repeated washing with $\mathrm{n}$-hexane and dried to obtain A. senegalensis crystals (AS2) $(2.8 \mathrm{~g} ; 5.6 \% \mathrm{w} / \mathrm{w})$ which was stored in a refrigerator for activity studies. 
2.6. Phytochemical Tests. The preliminary phytochemical analysis of methanol-methylene chloride extract (MME), ethyl acetate fraction (EF), hexane fraction (HF), methanol fraction (MF), and ethyl acetate subfraction isolated compound, AS2 were performed using standard phytochemical procedures as described by Harborne [20] and Trease and Evans [21]. Briefly, frothing test for saponins, Salkowski test for terpenoids, Liebermann-Burchard tests for steroids, ferric chloride test for tannins, Keller-Killiani test for cardiac glycosides, Dragendorff's and Mayer's test for alkaloids, Fehling's test for reducing sugars, xanthoproteic test for proteins, iodine test for carbohydrates or starch, and ammonia test for detection of flavonoids were performed for qualitative identification of the phytoconstituents present in [22]. All reagents for the preliminary phytochemical analysis were freshly prepared.

2.7. Identification and Characterization of AS2. Structural elucidation of the pure crystals, AS2, was performed using proton NMR and X-ray crystallography, since the compound is in crystal form. The melting point of AS2 was also determined using an analog melting point apparatus (Electrothermal, Cat. no. IA 6304, England). The identity was established by comparison of the spectral data and X-ray crystallography of previously published compounds [23].

2.8. Acute Toxicity and Lethality $\left(L D_{50}\right)$ Test of AS2. The oral acute toxicity and lethality test (LD50) of the AS2 was performed in mice using the method described by Lorke [24]. Briefly, the test was performed in two stages. In stage one, animals received oral administration of one of 10,100 , and $1000 \mathrm{mg} / \mathrm{kg}(n=3)$ of AS2 and observed for $24 \mathrm{~h}$ for number of deaths. Since no death occurred in any of the groups in the first stage of the test, in stage two of the test, 1600, 2900, and $5000 \mathrm{mg} / \mathrm{kg}$ doses of the AS2 were administered to a fresh batch of animals $(n=1)$ and was also monitored for $24 \mathrm{~h}$. Since death occurred at the maximum dose $(5000 \mathrm{mg} / \mathrm{kg})$, the $\mathrm{LD}_{50}$ was estimated as the product of the square root of the dose that recorded death and the dose that recorded no death preceding it (in this case, $2900 \mathrm{mg} / \mathrm{kg}$ dose). We have estimated and reported the acute toxicities and lethality tests of MME, EF, HF, and MF in a separate study [18].

2.9. GCMS Analysis of the Lipophilic Fraction (F1). The gas chromatography mass spectrometry (GCMS) of F1, the lipophilic subfraction, of the EF fractions was analyzed using GCMS-QP2010 PLUS (SHIMADZU, JAPAN) in order to characterize the lipophilic components. Sample of the F1 was suspended in $1 \mathrm{~mL}$ of ethyl acetate (Merck, Germany) and $1: 1$ of this solution was analyzed by the gas chromatography coupled with mass spectrometry equipped with a fused silica capillary column DB-5 $(30 \mathrm{~m} \times 0.25 \mathrm{~mm} \times 0.25 \mathrm{~m})$. The electron impact technique $(70 \mathrm{eV})$ was used with the injector temperature at $240^{\circ} \mathrm{C}$ and that of the detector at $230^{\circ} \mathrm{C}$. The carrier gas was helium at the working rate of $1.7 \mathrm{~mL} / \mathrm{min}$. The column temperature was initially $60^{\circ} \mathrm{C}$ and then was gradually increased at the rate of $3{ }^{\circ} \mathrm{C} / \mathrm{min}$ up to $240^{\circ} \mathrm{C}$. For detection of the oil components, we used a flame ionization detector set up at $230^{\circ} \mathrm{C}$. The identification of the components of the lipophilic fraction was effected through comparison of substance mass spectrum with the database of the GC/MS (NIST 62.lib), the literature, and retention index $[25,26]$.

2.10. Antimicrobial Assay. Each of the extract (MME), fractions (HF, EF, and MF), F1 and AS2 was dissolved in dimethyl sulfoxide (DMSO) to obtain $100 \mathrm{mg} / \mathrm{mL}$ concentration. Subsequently, the concentration was diluted to obtain 50,25 , 12.5 , and $6.25 \mathrm{mg} / \mathrm{mL}$ for the determination of the minimum inhibitory concentration (MIC) at the dose levels. Agar well diffusion method as described in $[27,28]$ was employed for the assay. The test organisms, the clinical isolates, were prepared with a $0.5 \mathrm{McFarland}$ standard and subcultured at $37^{\circ} \mathrm{C}$ and maintained on nutrient agar media for bacteria and sabouraud agar media for fungi (Aspergillus niger and Candida albicans). Petriplates containing $20 \mathrm{~mL}$ of respective medium were seeded with selected microbial strains and incubated at $37^{\circ} \mathrm{C}$ for 24 hours. Standard antimicrobial agents used as positive controls were gentamycin (Lek, Slovakia) and ciprofloxacin (Medreich, India). After 24 hours the inhibition zone diameters (IZD) were recorded and the mean calculated. The minimum inhibitory concentrations (MICs) were then determined at various dilutions by extrapolation from the graphs of IZD squared $\left(\mathrm{IZD}^{2}\right)$ against logarithm of the concentration.

2.11. Statistical Analysis. Data obtained were analysed by SPSS (Version 14) using One-Way Analysis of Variance (ANOVA) with Dunnet its test for multiple comparisons with the control. Values are in mean \pm SEM and were considered significant at $P<0.05$.

\section{Results}

3.1. Phytochemical Tests. Phytochemical tests of methanolmethylene chloride extract (MME) gave positive reactions with phytochemical reagents with respect to alkaloids, carbohydrates, flavonoids, fats and oils, glycosides, reducing sugars, resins, steroids, saponins, and terpenoids. The ethyl acetate (EF) gave positive reactions for alkaloids, flavonoids, resins and terpenoids, while AS2 gave a strong positive reaction with Salkowski test. The phytoconstituents of hexane fraction (HF) and methanol fraction (MF) were also shown (Table 2).

3.2. Acute Toxicity and Lethality $\left(L D_{50}\right)$ Test of AS2. The medium lethal dose $\left(\mathrm{LD}_{50}\right)$ of the AS2 was found to be $3800 \mathrm{mg} / \mathrm{kg}$ in mice indicating the good level of safety.

3.3. Identification and Characterization of AS2. The AS2 was shown to be a white crystalline and odourless compound. The results of the proton NMR and X-ray crystallography, when compared with the spectral data of known compounds, established the identity of AS2 to be kaur-16-en-19-oic acid or kaurenoic acid, a diterpenoid, with the chemical structure 
TABLE 2: Phytochemical constituents of extract and fractions.

\begin{tabular}{|c|c|c|c|c|c|}
\hline Constituent & MME & $\mathrm{EF}$ & $\mathrm{HF}$ & MF & AS2 \\
\hline Carbohydrate & + & - & - & + & - \\
\hline Alkaloid & + & + & + & + & - \\
\hline Reducing sugar & + & - & - & + & - \\
\hline Glycoside & + & - & - & + & - \\
\hline Saponins & + & - & - & + & - \\
\hline Tannins & - & - & - & - & - \\
\hline Flavonoids & + & + & - & - & - \\
\hline Resin & + & + & + & + & - \\
\hline Fats and oils & + & + & + & - & - \\
\hline Steroids & + & - & + & + & - \\
\hline Terpenoids & + & + & + & + & + \\
\hline $\begin{array}{l}\text { Acidic } \\
\text { compounds }\end{array}$ & + & + & - & - & - \\
\hline
\end{tabular}

${ }^{+}=$present $^{-}=$absent.

and X-ray crystallograph as shown (Figures 1, 2 and 3). The melting point of AS2 was found to be $170-172^{\circ} \mathrm{C}$.

3.4. GCMS Analysis of the Lipophilic Fraction (F1). The GCMS analysis of F1 revealed the presence of the following 6 major constituents which include kaur-16-en19-oic acid, 1-dodecanol, 1-naphthalenemethanol, 6,6dimethyl-bicyclo [3.1.1] hept-2-ene-2-ethanol, 3,3-dimethyl2-(3-methylbuta-1,3-dienyl)cyclohexan-1-methanol, and 3hydroxyandrostan-17-carboxylic acid (Table 3 ). The chemical structures of these constituents are shown in Figure 4.

3.5. Antimicrobial Assay. The extract, fractions, and AS2 exhibited significant antibacterial activity and are devoid of any antifungal activity. The results of the inhibition zone diameter (IZD) and MICs of the extract and fractions revealed activity against gram-positive and gram-negative organisms (Table 4). The order of potency against the various bacteria isolates with respect to their MICs by the extract and fractions was B. subtilis (AS2 > F1 > HF $\equiv \mathrm{MF}>\mathrm{EF}$ $>\mathrm{MME}$ ), S. aureus (AS2 > MME), and P. aeruginosa (F1 $>$ MME) (Table 5). The MME exhibited an MIC of 0.370 , $8.75,1.08$, and $0.07 \mathrm{mg} / \mathrm{mL}$ against the clinical isolates of $B$. subtilis, $S$. aureus, $P$. aeruginosa, and $S$. typhi, respectively. The extracts and isolate showed no antibacterial activity against E. coli (Table 4). The F1 gave an MIC of 0.06 and $0.04 \mathrm{mg} / \mathrm{mL}$ against $B$. subtilis and $P$. aeruginosa, respectively. AS2 has potency against $S$. aureus and $B$. subtilis with an MIC of 0.15 and $0.03 \mathrm{mg} / \mathrm{mL}$, respectively, whereas EF offered an MIC of $0.18 \mathrm{mg} / \mathrm{mL}$ against B. subtilis (Table 5). However, the antifungal test for MME, EF, HF, MF, F1, and AS2 against $A$. niger and $C$. albicans showed no activity.

\section{Discussion}

The antimicrobial effects of the methanol-methylene chloride extract (MME), ethyl acetate fraction (EF), hexane

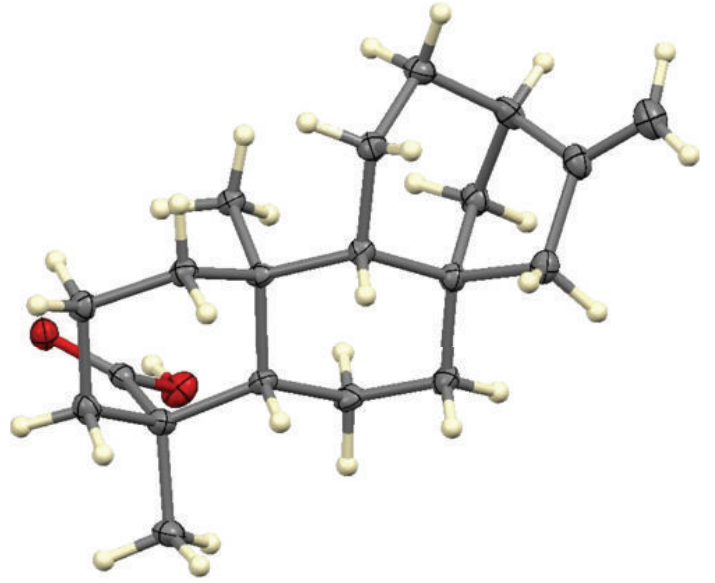

FIgURE 1: X-ray crystallograph of AS2.

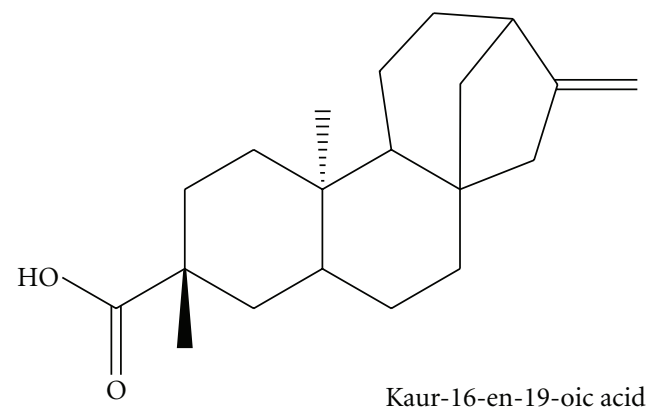

FIgUre 2: Chemical structure of AS2.

fraction (HF), methanol fraction (MF), the lipophilic subfraction (F1), and the isolated compound, AS2 exhibited appreciable antibacterial effects but are devoid of antifungal activity. However, AS2 exhibited the lowest MIC value of $30 \mu \mathrm{g} / \mathrm{mL}$ against B. subtilis and therefore exhibited the most potent activity when compared to the extracts and fraction of the root bark of $A$. senegalensis. The results of the proton 


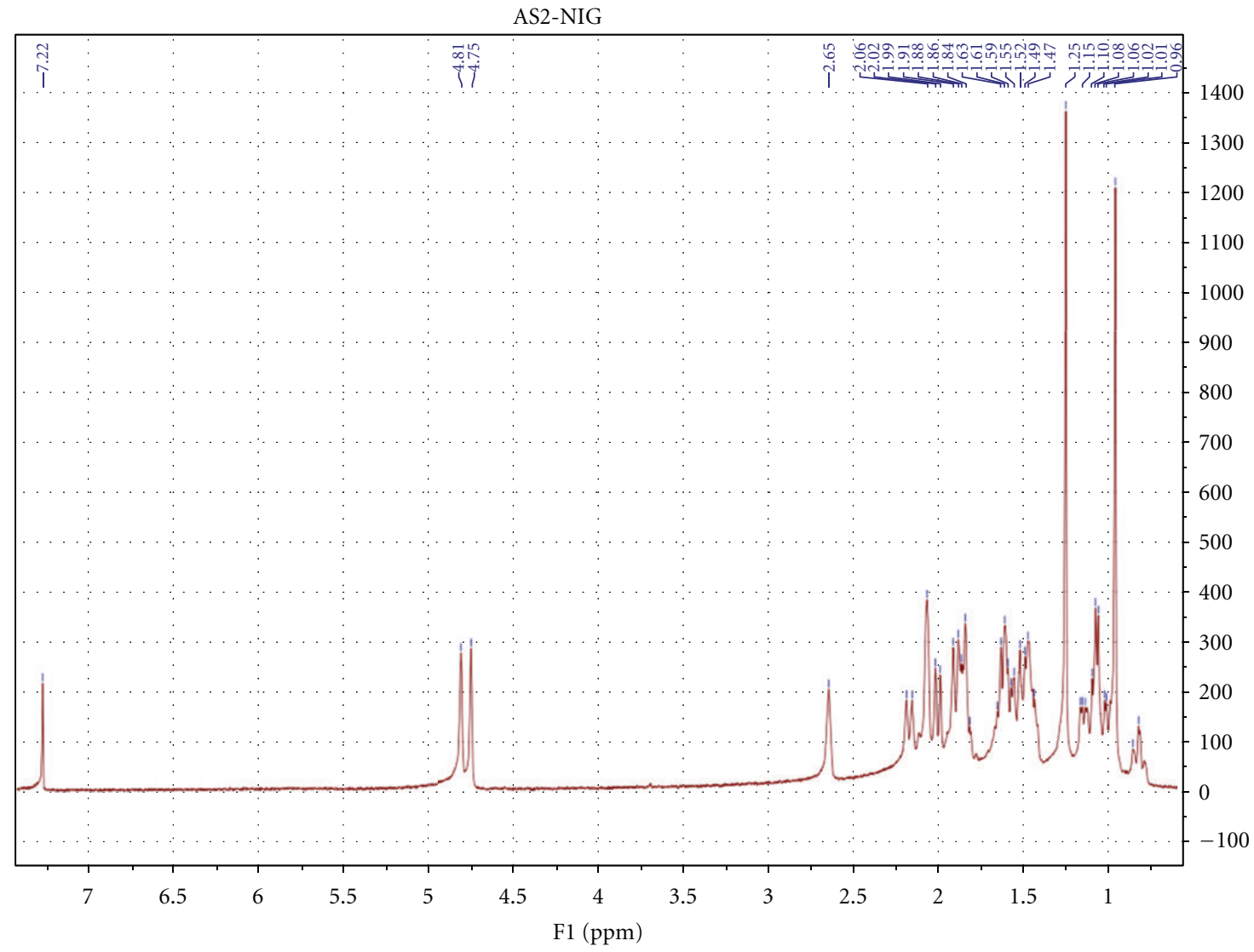

\begin{tabular}{ll} 
Parameter & \multicolumn{1}{c}{ Value } \\
H:/AS2-NIG/3/fid \\
AS2-NIG \\
(2) Title & Bruker BioSpin GmbH \\
(4) Comment & Damaris \\
(5) Owner & Spect \\
Site & \\
Spectrometer & CDCI3 \\
S) Solvent & 298.2 \\
10) Temperature & Zg30 \\
1) Pulse sequence & $1 D$ \\
2) Experiment & 8
\end{tabular}

Parameter

(14) Receiver gain

(15) Relaxation delay

(16) Pulse width

(17) Acquisition time

(18) Acquisition date

(19) Modification date

(20) Spectrometer frequercy

(21) Spectral width

(22) Lowest frequency

(23) Nucleus

(24) Acquired size

(25) Spectral size
Value

362

1.0000

10.2500

3.9846

2010-10-03T10:48:06

2010-10-03T10:48:06

400.15

8223.7

$-1640.8$

$1 \mathrm{H}$

32768

65536

FIgURE 3: Spectral data analysis of AS2.

NMR and X-ray crystallography identified and characterized AS2 to be a diterpene known as kaur-16-en-19-oic acid or kaurenoic acid (KA). The melting point of AS2 was found to be $170-172^{\circ} \mathrm{C}$ which was of a comparable range with that of kaurenoic acid from a different source already reported [29]. In a separate study, the antibacterial effects of the essential oil from A. senegalensis have been reported [12] and more importantly the antibacterial activity of kaurenoic acid from the root extract of another plant, Viguiera arenaria, has been documented [30]. The extracts, F1 and the KA, exhibited better antibacterial effects against gram-positive organisms such as B. subtilis and $S$. aureus, than the gram-negative rods such as $P$. aeruginosa, $S$. paratyphi, and E. coli used in the study.
Therefore, the antibacterial effects of MME, EF, HF, MF, F1, and AS2 against organisms such as $P$. aeruginosa and $S$. aureus correlated with the ethnomedicinal use of the plant in wound healing, since $P$. aeruginosa and $S$. aureus had been implicated in the contamination of wounds and boils [31]. The antibacterial activity against $P$. aeruginosa is of interest because $P$. aeruginosa has been reported to be resistant to many antibacterial agents and identified as an opportunistic pathogen which causes complications in immune-compromised patients [32]. The activity of root bark extracts of $A$. senegalensis against $S$. aureus has also been documented in a separate study [13]. Moreover, according to Apak and Olila [13], the root bark extract of A. senegalensis exhibited no activity against $E$. coli which was consistent with 
TABLE 3: Chemical constituents of lipophilic fraction (F1).

\begin{tabular}{|c|c|c|c|c|c|}
\hline S/No & Chemical name & $\begin{array}{l}\text { Molecular } \\
\text { formula }\end{array}$ & $\begin{array}{l}\text { Molecular } \\
\text { weight }\end{array}$ & $\begin{array}{c}\text { Retention } \\
\text { (KOVAT's) } \\
\text { index } \\
\end{array}$ & MS ions/fragments (m/e) \\
\hline 01 & 1-dodecanol & $\mathrm{C}_{12} \mathrm{H}_{26} \mathrm{O}$ & 186 & 1457 & $\begin{array}{c}27,41,55,70,83,97 \\
111(112), 126,140\end{array}$ \\
\hline 02 & $\begin{array}{l}\text { 6,6-dimethyl-bicyclo } \\
\text { [3.1.1]hept-2-ene-2- } \\
\text { ethanol }\end{array}$ & $\mathrm{C}_{11} \mathrm{H}_{18} \mathrm{O}$ & 166 & 1290 & $\begin{array}{c}27,41(43), 67,79,91,105 \\
122,151 .\end{array}$ \\
\hline 03 & Kaur-16-en-18-oic acid & $\mathrm{C}_{21} \mathrm{H}_{32} \mathrm{O}_{2}$ & 316 & 2056 & $\begin{array}{c}27,41,55,67,79,91,105 \\
121,133,147,159,187 \\
213,241,257,273,301 \\
316 .\end{array}$ \\
\hline 04 & 1-naphthalenemethanol & $\mathrm{C}_{15} \mathrm{H}_{26} \mathrm{O}$ & 222 & 1685 & $\begin{array}{c}27,41,55,69,81,109,124 \\
191,222 .\end{array}$ \\
\hline 05 & $\begin{array}{l}\text { 3,3-dimethyl-2-(3- } \\
\text { methylbuta-1,3-dienyl) } \\
\text { cyclohexan-1-methanol }\end{array}$ & $\mathrm{C}_{14} \mathrm{H}_{24} \mathrm{O}$ & 208 & 1592 & $\begin{array}{c}41,55,69,81,95,109,123 \\
139,165,177,193 .\end{array}$ \\
\hline 06 & $\begin{array}{l}\text { 3-hydroxyandrostan-17- } \\
\text { carboxylic } \\
\text { acid }\end{array}$ & $\mathrm{C}_{20} \mathrm{H}_{32} \mathrm{O}_{3}$ & 320 & 2375 & $\begin{array}{l}43,67,79,93,108,121 \\
135,147,161,175,194 \\
215,233,248,287,302 .\end{array}$ \\
\hline
\end{tabular}<smiles>CCCCCCCCCCCCCO</smiles>

(1)<smiles>C=C1CC23CCC4CC(C)(C(=O)O)CCC4(C)C2CCC1C3</smiles>

(3)

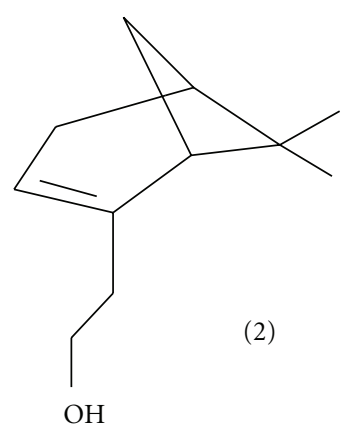

(5)<smiles>C=C(C)/C=C/C1C(CO)CCCC1(C)C</smiles><smiles>CCC1C(C)=CCC2C(C)(C)CCCC12C</smiles>

(4)

FIgURE 4: Chemical structures of GCMS constituents of F1. 


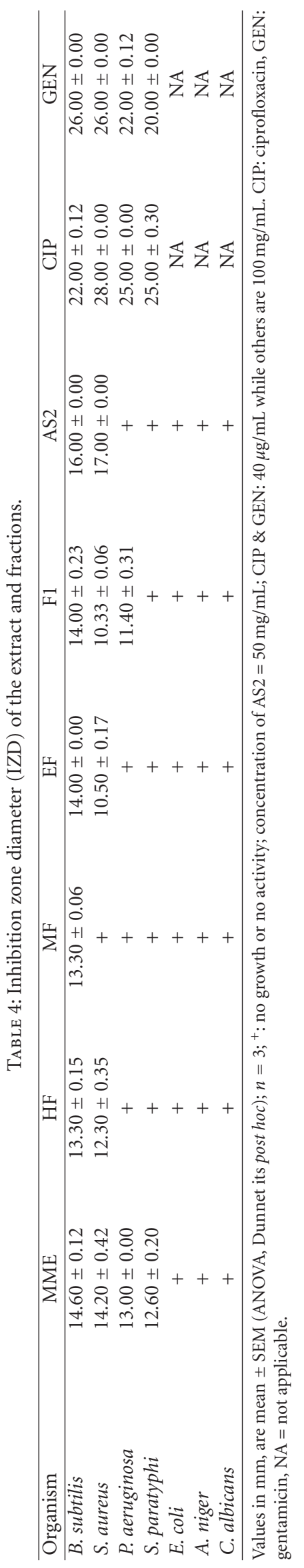


TABLe 5: Minimum inhibitory concentration (MIC) of extract and fractions.

\begin{tabular}{lcccccccc}
\hline ORGANISM & MME & MF & HF & EF & F1 & AS2 & CIP & GEN \\
\hline B. subtilis & 370.00 & 150.00 & 140.00 & 180.00 & 60.00 & 30.00 & 0.28 & 0.02 \\
S. aereus & 8750.00 & + & + & + & + & 150.00 & 1.18 & 0.23 \\
P. aeruginosa & 1080.00 & + & + & + & 40.00 & + & 3.60 & 0.79 \\
S. paratyphi & 70.00 & + & + & + & + & + & 0.39 & 1.77 \\
\hline
\end{tabular}

MIC values are in $\mu \mathrm{g} / \mathrm{mL}$.

the lack of activity of MME, EF, HF, MF, F1, and AS2 against E. coli identified in this study.

In addition to the antibacterial action of KA, there is the possibility of the presence of other phytochemicals contributing to the antibacterial activity of the extracts and fractions of $A$. senegalensis. This is more so since the F1, which consisted 6 major constituents, together with KA, exhibited potent antibacterial activity with an MIC of $40 \mu \mathrm{g} / \mathrm{mL}$ against $P$. aeruginosa, whereas the kaurenoic acid alone did not show appreciable activity against $P$. aeruginosa. Hence, due to the presence of six major phytochemicals in the GC-MS analysis of the F1, the observed antibacterial effects could be attributed to the combined or single effects of any of the compounds which include kaur-16-en-19-oic acid, 1-dodecanol, 1-naphthalenemethanol, 6,6-dimethyl-bicyclo [3.1.1] hept-2-ene-2-ethanol, 3,3-dimethyl-2-(3-methylbuta-1,3-ienyl)cyclohexan-1-methanol, and 3-hydroxyandrostan-17-carboxylic acid. The presence of kaurenoic acid among these compounds is of practical interest as it was also established as the pure isolated compound, AS2. The kaurenoic acid from the F1 gave the following mass ions on fragmentation with the GCMS analysis: 316 (molecular ion), 301 (demethylation), and 273 (decarboxylation). Notably, steroids, organic acids, and alcohols dominated the remaining 5 compounds of the $\mathrm{F} 1$ and both organic acids as well as alcohols are known to possess antibacterial activity especially at higher concentrations [3]. However, F1 showed a strong indication and possibility of being a fixed oil, since it possesses some characteristics attributable to fixed oils which include odorless liquid at room temperature, pale yellowish in colour, permanent grease spot on filter paper when heated in an oven and often contains mixture of organic acids as well as being an extraction product of $\mathrm{n}$-hexane or mixture of $\mathrm{n}$-hexane and ethyl acetate [33]. Medicinal plants with preponderance of variety of secondary metabolites, such as tannins, terpenoids, essential oils, alkaloids, and flavonoids have been found in vitro, to possess antimicrobial properties [3]. There is a recognizable loss of activity due to fractionation as the crude extract, MME, exhibited activity against all the organisms tested except $E$. coli, whereas the fractions were found to have lost activity to some of the tested organisms especially $S$. paratyphi. The presence of diterpenoid compounds in the extracts and fractions of $A$. senegalensis really correlated well with the high presence of resins in plants as diterpene acids occur well in plant resins. Some other published works have reported the isolation of kaurenoic acid from the leaves of $A$. senegalensis $[34,35]$ and aerial parts of Espeletia semigloburata [36] which exhibited antibacterial, anticancer, anti-inflammatory, and antipyretic effects. The lack of activity against fungal organism, $C$. albicans, in the study was in consistent with other reported work on root bark extract of $A$. senegalensis which exhibited lack of activity against $C$. albicans [16]. In other documented studies, terpenoids have shown to possess antibacterial $[3,37$, $38]$, antiviral [39, 40], and antiprotozoal effects [41]. Particularly, antibacterial effects of diterpenoids isolated from other plants have been reported $[42,43]$. The results from this study tend to support the ethnomedicinal claim of root bark of A. senegalensis in treatment of bacterial infections and wound healing particularly in the treatment urinary tract infections in veterinary animals [13]. Furthermore, KA could equally serve as a veritable lead compound in the development of potent standard antibacterial agent.

\section{Conclusion}

Results of the study have indicated that a diterpenoid, kaur16-en-19-oic acid or kaurenoic acid, has been identified as the phytochemical constituent responsible for the antibacterial effects of root bark of Nigerian Annona senegalensis Pers. (Verbenaceae) and is devoid of appreciable antifungal effects.

\section{Conflict of Interests}

The authors declare that there is no conflict of interests.

\section{Acknowledgments}

The authors thankfully appreciate Professor Dr. Mark Hamann of the Department of Pharmacognosy and Phytochemistry, University of Mississippi, USA, for performing the proton NMR and the X-ray crystallography of AS2. Part of the financial support was from the Ministry of Education, Science and Technology Post Basic Programme, of the Federal Government of Nigeria for the Innovators of Tomorrow (IOT) Award Grant of the World Bank assisted Step-B project.

\section{References}

[1] D. Livermore, "Can better prescribing turn the tide of resistance?” Nature Reviews Microbiology, vol. 2, no. 1, pp. 73-78, 2004.

[2] J. G. Choi, S. I. Jeong, C. S. Ku et al., "Antibacterial activity of hydroxyalkenyl salicylic acids from sarcotesta of ginkgo biloba 
against vancomycin-resistant enterococcus," Fitoterapia, vol. 80, no. 1, pp. 18-20, 2009.

[3] M. M. Cowan, "Plant products as antimicrobial agents," Clinical Microbiology Reviews, vol. 12, no. 4, pp. 564-582, 1999.

[4] R. Salazar-Aranda, L. Perez-Lopez, J. Lopez-Arroyo, and N. Waksman de Torres, "Antimicrobial and antioxidant activities of plants from Northeast of Mexico," Evidence-Based Complementary and Alternative Medicine, vol. 2011, Article ID 536139, 6 pages, 2011.

[5] A. S. Sofowora, Medicinal Plants and Traditional Medicine in Africa, Spectrum Books, Ibadan, Nigeria, 3rd edition, 2008.

[6] G. Y. Lescher, E. D. Froelich, M. D. Gruet, J. H. Bailey, and R. P. Brundage, "1,8-Naphthyridine derivatives: a new class of chemotherapeutic agents," Journal of Medical and Pharmaceutical Chemistry, vol. 5, pp. 1063-1068, 1962.

[7] G. Yuvaraj, V. Sathyanathan, S. Shankar, and N. R. Kumar, "Anticancer and in-vitro activities of Derris brevipes Var brevipes," Journal of Chemical and Pharmaceutical Research, vol. 2, no. 6, pp. 482-488, 2010.

[8] Y. Bibi, S. Nisa, F. M. Chaudhary, and M. Zia, "Antibacterial activity of some selected medicinal plants of pakistan," BMC Complementary and Alternative Medicine, vol. 11, article 52, 2011.

[9] A. Brantner and E. Grein, "Antibacterial activity of plant extracts used externally in traditional medicine," Journal of Ethnopharmacology, vol. 44, no. 1, pp. 35-40, 1994.

[10] J. C. N. Assob, H. L. F. Kamga, D. S. Nsagha et al., "Antimicrobial and toxicological activities of five medicinal plant species from Cameroun traditional medicine," BMC Complementary and Alternative Medicine, vol. 11, article 70, 2011.

[11] D. N. Muanza, B. W. Kim, K. L. Euler, and L. Williams, "Antibacterial and antifungal activities of nine medicinal plants from zaire," International Journal of Pharmacognosy, vol. 32, no. 4, pp. 337-345, 1994.

[12] A. Samie, C. L. Obi, P. O. Bessong, and L. Namrita, "Activity profiles of fourteen selected medicinal plants from rural venda communities in south africa against fifteen clinical bacterial species," African Journal of Biotechnology, vol. 4, no. 12, pp. 1443-1451, 2005.

[13] L. Apak and D. Olila, "The in-vitro antibacterial activity of Annona senegalensis, Securidacca longipendiculata and Steganotaenia araliacea-Ugandan medicinal plants," African Health Sciences, vol. 6, no. 1, pp. 31-35, 2006.

[14] A. C. Kudi and S. H. Myint, "Antiviral activity of some Nigerian medicinal plant extracts," Journal of Ethnopharmacology, vol. 68, no. 1-3, pp. 289-294, 1999.

[15] M. M. Suleiman, T. Dzenda, and C. A. Sani, "Antidiarrhoeal activity of the methanol stem-bark extract of Annona senegalensis pers. (Annonaceae)," Journal of Ethnopharmacology, vol. 116, no. 1, pp. 125-130, 2008.

[16] G. More, T. E. Tshikalange, N. Lall, F. Botha, and J. J. M. Meyer, "Antimicrobial activity of medicinal plants against oral microorganisms," Journal of Ethnopharmacology, vol. 119, no. 3, pp. 473-477, 2008.

[17] T. C. Okoye, P. A. Akah, and C. P. Omeke, "Evaluation of the anticonvulsant and muscle relaxant effects of the methanol root bark extracts of Annona senegalensis," Asian Pacific Journal of Tropical Medicine, vol. 3, no. 1, pp. 25-28, 2010.

[18] T. C. Okoye and P. A. Akah, "Anticonvulsant and sedative effects of root bark extract and fractions of Annona senegalensis," Inventi Impact, vol. 1, no. 2, pp. 100-104, 2010.

[19] T. C. Okoye, P. A. Akah, A. C. Ezike, and J. C. Nwoye, "Studies on the effects of Annona senegalensis root bark extract on acute and chronic inflammation in rats," Journal of Pharmacy Research, vol. 4, no. 5, pp. 1443-1444, 2011.

[20] J. B. Harborne, Phytochemical Methods: A Guide to Modern Techniques of Plant Analysis, Chapman and Hall, London, UK, 2nd edition, 1988.

[21] G. E. Trease and W. C. Evans, Test book of Pharmacognosy, Brailliare Tindall and Macmillian, London, UK, 11th edition, 1989.

[22] A. S. Sofowora, Medicinal Plants and Traditional Medicine in Africa, Spectrum Books, Ibadan, Nigeria, 3rd edition, 2008.

[23] C. Brassy, B. Bachet, and E. Wollenweber, "Acide decahydro1,2,3,4,5,6,7,8,9,10-dimethyl-1,4a (methylene-1) ethano-7,8a phenanthrenecarboxylique-1, acide (-)- kaurene-16 oique19," Acta Crystallographica C, vol. 44, pp. 528-531, 1988.

[24] D. Lorke, "A new approach to practical acute toxicity testing," Archives of Toxicology, vol. 54, no. 4, pp. 275-287, 1983.

[25] F. W. McLafferty and D. Stauffer, The Wiley/NBS Registry of Mass Spectral Data, vol. 1-2, John Wiley \& Sons, New York, NY, USA, 1989.

[26] R. P. Adams, Identification of Essential Oil Components by Gas Chromatography/ Mass Spectroscopy, Allured Publishing, Carol Stream, Ill, USA, 1995.

[27] V Lovian, Antibiotics in Laboratory Medicine, Williams and Williams, Baltimore, Md, USA, 1980.

[28] C. Perez, M. Paul, and P. Bazerque, "An antibiotic assay by the agar well-diffusion method," Acta Biologiae et Medicine Experimentalis, vol. 15, pp. 113-115, 1990.

[29] N. L. Daló, M. C. Sosa-Sequera, and A. Usubillaga, "On the anticonvulsant activity of kaurenic acid," Investigacion Clinica, vol. 48, no. 3, pp. 349-358, 2007.

[30] T. S. Porto, R. Rangel, N. A. J. C. Furtado et al., "Pimaranetype diterpenes: antimicrobial activity against oral pathogens," Molecules, vol. 14, no. 1, pp. 191-199, 2009.

[31] C. O. Okoli, P. A. Akah, and A. S. Okoli, "Potentials of leaves of Aspilia africana (Compositae) in wound care: an experimental evaluation," BMC Complementary and Alternative Medicine, vol. 7, article 24, 2007.

[32] G. O. Adeshina, T. S. Tahir, and J. A. Onaolapo, "Microbiological evaluation of packaged pineapple juice marketed in Kaduna metropolis," Nigerian Journal of Pharmaceutical Research, vol. 8, no. 1, pp. 281-287, 2010.

[33] P. K. Mukherjee, Quality Control of Herbal Drugs: An Approach to Evaluation of Botanicals, Business Horizons, New Delhi, India, 1st edition, 2007.

[34] I. T. U. Eshiet, A. Akisanya, and D. A. H. Taylor, "Diterpenes from Annona senegalensis," Phytochemistry, vol. 10, no. 12, pp. 3294-3295, 1971.

[35] M. O. Fatope, O. T. Audu, Y. Takeda et al., "Bioactive entkaurene diterpenoids from Annona senegalensis," Journal of Natural Products, vol. 59, no. 3, pp. 301-303, 1996.

[36] M. C. Sosa-Sequera, O. Suárez, and N. L. Daló, "Kaurenic acid: an in vivo experimental study of its anti-inflammatory and antipyretic effects," Indian Journal of Pharmacology, vol. 42, no. 5, pp. 293-296, 2010.

[37] I. Kubo, H. Muroi, and M. Himejima, "Antibacterial activity of totarol and its potentiation," Journal of Natural Products, vol. 55, no. 10, pp. 1436-1440, 1992.

[38] L. Mendoza, M. Wilkens, and A. Urzúa, "Antimicrobial study of the resinous exudates and of diterpenoids and flavonoids isolated from some chilean Pseudognaphalium (Asteraceae)," Journal of Ethnopharmacology, vol. 58, no. 2, pp. 85-88, 1997. 
[39] T. Pengsuparp, L. Cai, H. H. S. Fong et al., "Pentacyclic triterpenes derived from Maprounea africana are potent inhibitors of hiv-1 reverse transcriptase," Journal of Natural Products, vol. 57, no. 3, pp. 415-418, 1994.

[40] H. D. Sun, S. X. Qiu, L. Z. Lin et al., "Nigranoic acid, a triterpenoid from Schisandra sphaerandra that inhibits hiv-1 reverse transcriptase," Journal of Natural Products, vol. 59, no. 5, pp. 525-527, 1996.

[41] S. Ghoshal, B. N. Krishna Prasad, and V. Lakshmi, "Antiamoebic activity of piper longum fruits against Entamoeba histolytica in vitro and in vivo," Journal of Ethnopharmacology, vol. 50, no. 3, pp. 167-170, 1996.

[42] O. Batista, A. Duarte, J. Nascimento, and M. F. Simoes, "Structure and antimicrobial activity of diterpenes from the roots of Plectranthus hereroensis," Journal of Natural Products, vol. 57, no. 6, pp. 858-861, 1994.

[43] S. Kadota, P. Basnet, E. Ishii, T. Tamura, and T. Namba, "Antibacterial activity of trichorabdal a from Rabdosia trichocarpa against Helicobacter pylori," Zentralblatt Fur Bakteriologie, vol. 286, no. 1, pp. 63-67, 1997. 


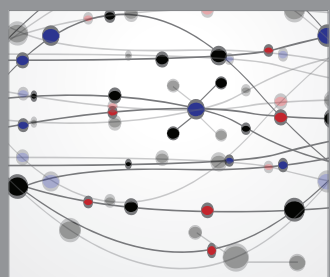

The Scientific World Journal
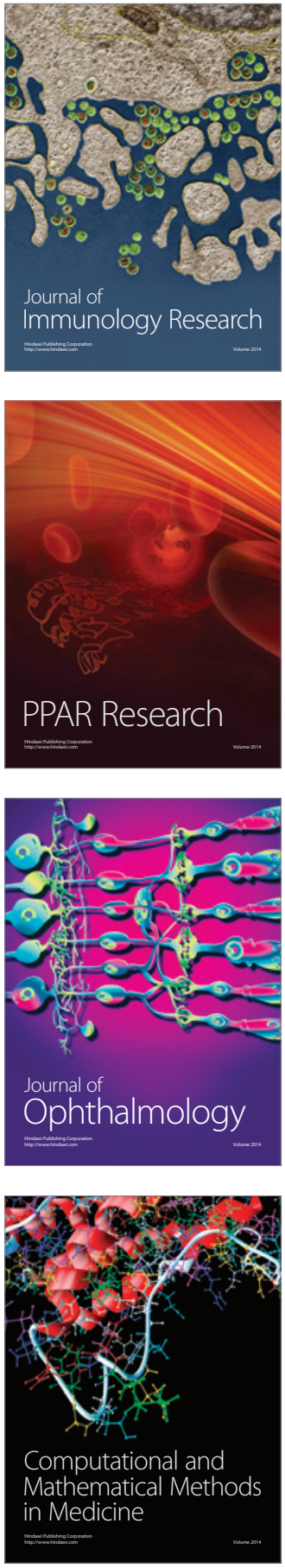

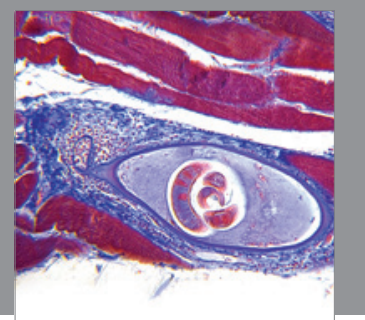

Gastroenterology

Research and Practice
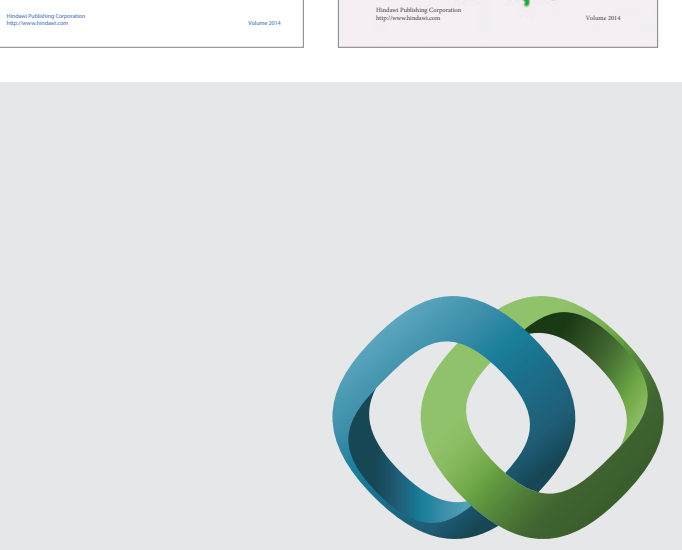

\section{Hindawi}

Submit your manuscripts at

http://www.hindawi.com
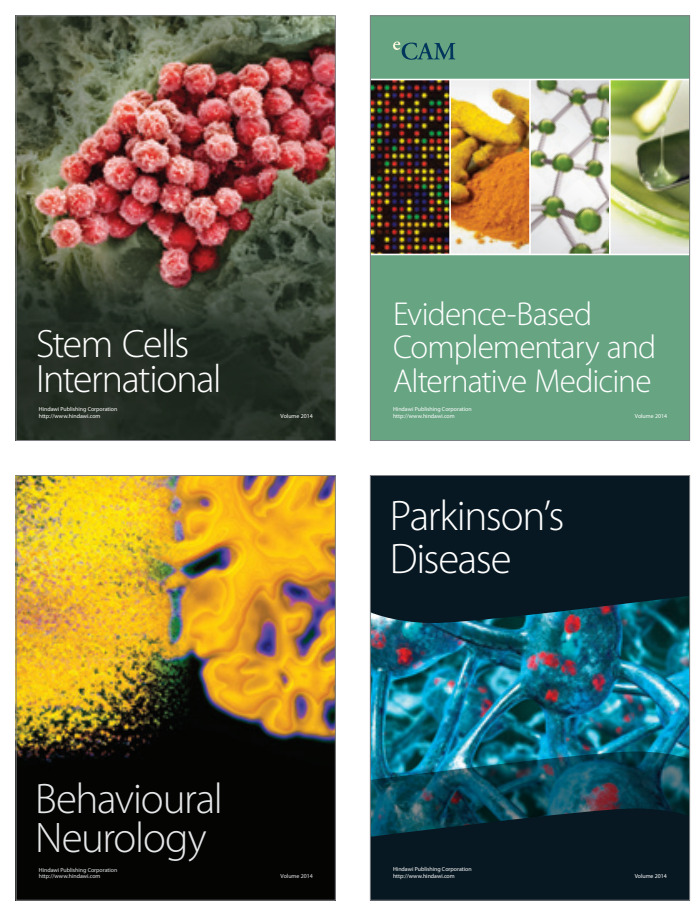

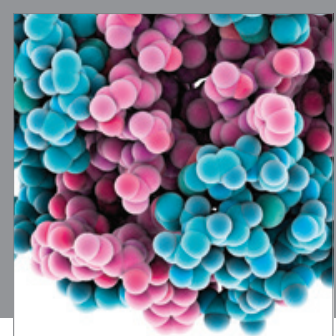

Journal of
Diabetes Research

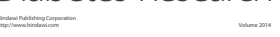

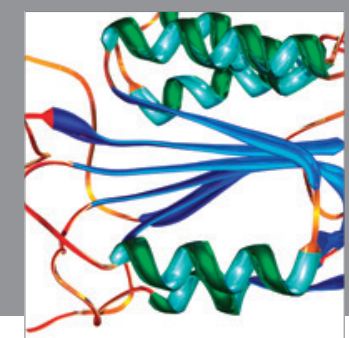

Disease Markers
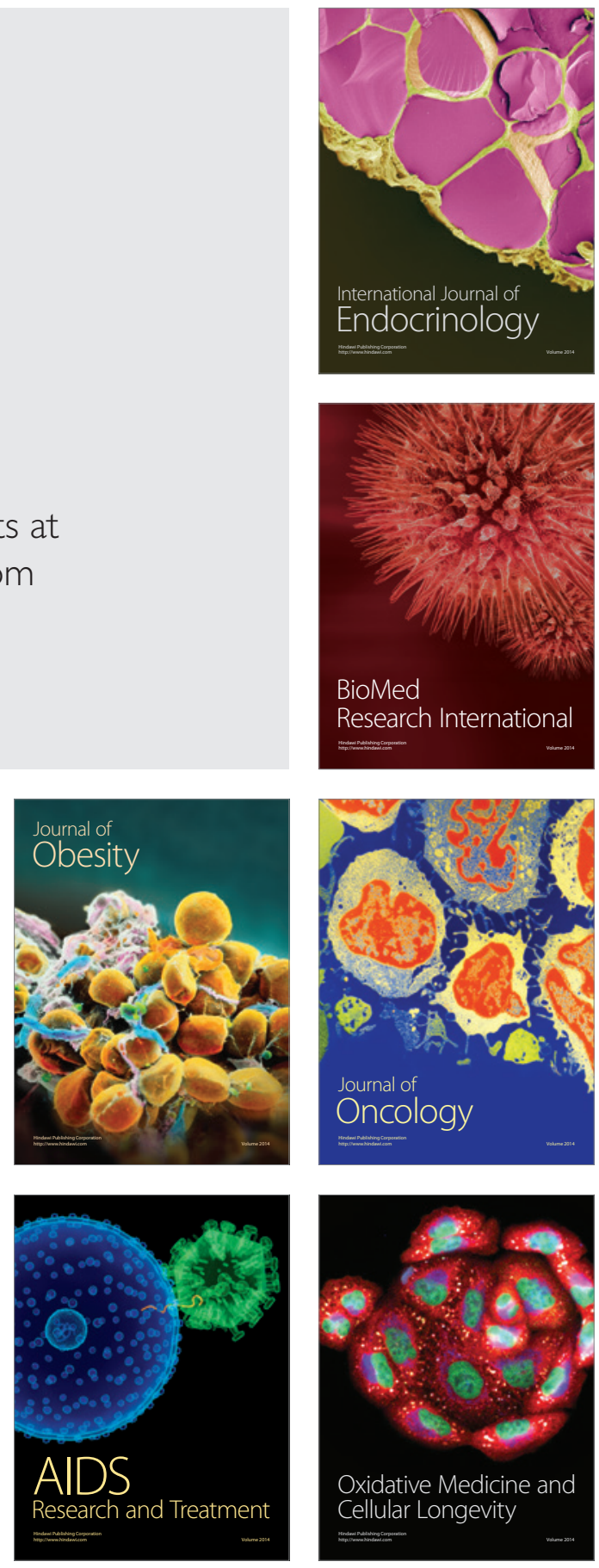